\title{
Analysis of Biodegradation and Microbial Growth in Groundwater System Using New the Homotopy Perturbation Method
}

\author{
${ }^{1} \mathrm{~S}$. Thamizh Suganya, ${ }^{2} \mathrm{~J}$. Visuvasam, ${ }^{3} \mathrm{P}$. Balaganesan, ${ }^{4} \mathrm{~L}$. Rajendran \\ ${ }^{1}$ Department of Mathematics, \\ AMET Deemed to be University, \\ Chennai-603112, India. \\ thamsuganms@gmail.com \\ ${ }^{2}$ Ramanujan Research Center in Mathematics, \\ Saraswathi Narayanan College, \\ Madurai -625022 , India. \\ visuvasam135@gmail.com \\ ${ }^{3}$ Department of Mathematics, \\ AMET Deemed to be University, \\ Chennai-603112, India. \\ Corresponding Author: \\ balaganesanpp@gmail.com \\ ${ }^{4}$ Department of Mathematics, \\ AMET, Deemed to be University, \\ Chennai-603112, India. \\ raj_sms@rediffmail.com.
}

Article History: Received: 11 January 2021; Accepted: 27 February 2021; Published online: 5 April 2021

\begin{abstract}
In this paper, we drive the concentration of microbial growth in the groundwater system. This model is based on the system of non-linear differential equations. The system of equations is solved by using the new homotopy perturbation method. We followed toluene degradation and bacterial growth by measuring toluene and oxygen concentrations and by direct cell counts. And the total amount of toluene degraded by Pseudomonal putida $\mathrm{F} 1$ in the sediment columns increased with rising concentration of the source and flow rate. In contrast, the efficiency of toluene removal slowly decreases. The approximate analytical expression of this model, the concentration of toluene and bacteria also consideration of a metabolite concentration, the microbial growth of attached and suspended bacteria, depending on the simultaneous presence of toluene. Finally, oxygen and dual Monod kinetics are discussed. The analytical solutions are also compared with simulation results and satisfactory the agreement is noted.
\end{abstract}

Keywords - Homotopy Perturbation Method; Microbial Growth in Groundwater System; Biodegradation; Numerical Simulation; Pseudomonal putida F1.

\section{INTRODUCTION}

The reliability of the design and cost-efficient bioremediation methods, the controls and limitations of the biodegradation potential of natural microbial communities in aquifers [1]. Petroleum hydrocarbons belongs to the most abundant contaminants in aquifers [2]. Among them, the nonaromatic compounds benzene, toluene, ethyl benzene, and xylene (BTEX) are of major concern due to their toxicity [3]. Recent research on the biodegradation of aromatic hydrocarbons in flow through laboratory and field experiments have shed some light on the limitation of biodegradation by transverse dispersive mixing [4]. While, data from natural aquatic systems hint at considerably lower values $[5,6]$. The media in the sediment column experiments, one containing the electron donor (toluene), and the other the electron acceptor (oxygen or nitrate). These were combined directly at the inlet of the column to prevent bacteria creeping back into the water reservoirs [7]. The new-growing cells are released into the mobile aqueous process in the model, and eventually flushed out of the base. This release of new-grown cells from the sediment surface to the mobile aqueous phase has already been observed under growth conditions in earlier studies on microbial transport $[8,9]$. MFC methods are innovative modes of restoring / reducing nutrients through waste water. The MFC can also be used to produce a wide range of organic problems, such as: wastewater from of the agro-industry, digested sludge, domestic wastewater, food wastewater, and marine sediments [10, 11]. Biosensors are analytical devices interpreting a biochemical recognition reaction into an observable effect [12]. In addition, the attachment to suspended cells ratio was the highest at the lowest concentrations of substrates, and vice versa. It is well trend from marine sediments like aquifers [13 - 16]. In additional factors such as food web interactions, grazing, or resource rivalry as well as multiple constraints play an important role within natural microbial communities [17]. 


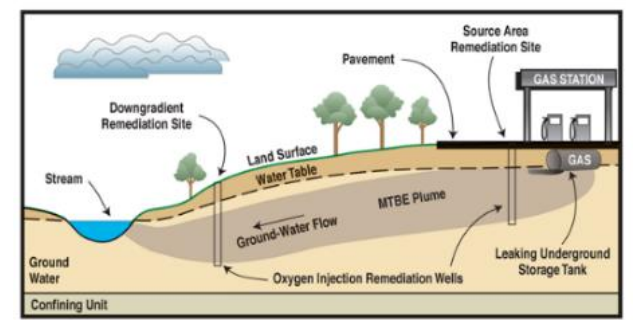

Fig.1: Microbial Growth in Groundwater System

In order to clean up hydro carbonates from soil and water, the latest development research is used such as Alberta techniques. This is an all-new approach to clean up polluted sites using bacteria to eat offending water particles while leaving the nice. Recently, Kirthiga and Rajendran [18] have obtained analytical expression on the concentrations of the output of biomass and ethanol from industrial wastewater. Presented a steady-state analysis of the MFC and the analytical expression of a substrate, anodophilic, methanogenic, and oxidized mediators obtained in all parameters using Homotopy perturbation method [19].

In this communication, the analytical expression for concentration profiles are derived using a new Homotopy perturbation method. The analytical expressions of concentrations of $X(t), c_{t o l}(t), c_{m e t}(t), c_{o x}(t), X_{a t t}(t)$ and $X_{m o b}(t)$ are obtained from new homotopy perturbation method is compared with simulation results is presented.

\section{Nomenclature}

\begin{tabular}{|c|c|}
\hline$X$ & Concentration of bacteria [cells L-1] \\
\hline$c_{m e t}$ & Concentration of the metabolite $[\mu \mathrm{M}]$ \\
\hline$c_{t o l}$ & Concentration of toluene $[\mu \mathrm{M}]$ \\
\hline$c_{o x}$ & Concentration of oxygen $[\mu \mathrm{M}]$ \\
\hline$X_{a t t}$ & $\begin{array}{l}\text { Concentration of attached, bacteria } \\
\text { [cell } L_{\text {sed }}^{-1} \text { ] }\end{array}$ \\
\hline$X_{m o b}$ & $\begin{array}{l}\text { Concentration of mobile bacteria [cells } \\
\left.L_{\text {sed }}^{-1}\right]\end{array}$ \\
\hline$K_{t o l}$ & $\begin{array}{l}\text { Half saturation concentration of toluene } \\
{[\mu \mathrm{M}]}\end{array}$ \\
\hline$K_{o x}$ & $\begin{array}{l}\text { Half-saturation concentrations } \\
\text { oxygen }[\mu \mathrm{M}]\end{array}$ \\
\hline$k_{\text {att }}$ & $\begin{array}{l}\text { First-order attachment rate coefficient } \\
\text { [S-1] }\end{array}$ \\
\hline$K_{\text {met }}$ & $\begin{array}{l}\text { Concentration of the metabolite with } \\
\text { the corresponding half-saturation } \\
\text { concentration }[\mu \mathrm{M}]\end{array}$ \\
\hline$Y$ & $\begin{array}{l}\text { Half saturation concentration of yield } \\
\text { coefficient }[\text { cells } / \mu \mathrm{mol}]\end{array}$ \\
\hline$\mu_{\max }$ & $\begin{array}{l}\text { Maximum specific growth rate constant } \\
\text { [S-1] }\end{array}$ \\
\hline$v$ & Velocity [m S-1] \\
\hline$D$ & Dispersion coefficient [m2 S-1] \\
\hline$X_{\text {att }}^{\max }$ & $\begin{array}{l}\text { Maximum carrying capacity of attached } \\
\text { bacteria [cells } L_{\text {sed }}^{-1} \text { ] }\end{array}$ \\
\hline$r_{\text {daughter }}$ & $\begin{array}{l}\text { Dynamic detachment rate [cells } L_{\text {sed }}^{-1} \mathrm{~S} \text { - } \\
\text { 1] }\end{array}$ \\
\hline$r_{\text {attach }}$ & $\begin{array}{l}\text { Modified first-order attachment rate } \\
\text { [cells L-1 S-1] }\end{array}$ \\
\hline
\end{tabular}

Biodegradation is the normal deterioration by microorganisms such as bacteria and fungi or other biological activity of the products. Composting is a mechanism powered by humans in which biodegradation occurs under a specified set of circumstances. The Mathematical modeling and solution of biodegradation reactions are as follows.

\section{A. Direct utilization of toluene for growth}


In the standard model, we assume that the bacteria directly grow on the degradation of toluene. The electron acceptor is considered available in excess, and biomass decay is neglected. Then the standard Monod equations read as follows [20]: $\frac{d X}{d t}=\mu_{\max } \cdot \frac{c_{t o l}}{c_{t o l}+K_{t o l}} \cdot X$

$\frac{d c_{t o l}}{d t}=-\frac{1}{Y} \frac{d X}{d t}$

The initial conditions are

$X(t)=X^{*}, c_{t o l}(t)=c_{\text {tol }}^{*} \quad$ at $\quad t=0$

where, $\mu_{\max }\left[S^{-1}\right]$ is the maximum specific growth rate constant, $X$ [cells $\left.L^{-1}\right]$ and $c_{t o l}[\mu M]$ are concentration of bacteria and toluene, $Y[\mu M]$ and $K_{t o l}[\mu M]$ are the half saturation concentration of yield coefficient and the toluene.

B. Analytical solutions of the direct utilization of toluene for growth

The analytical expression of concentration of bacteria $X(t)$ and toluene $c_{t o l}(t)$ are obtained as follows:

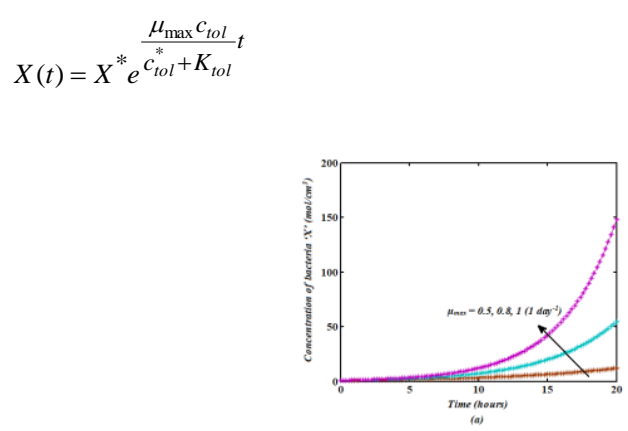

(4) $c_{t o l}(t)=c_{t o l}^{*}+\frac{X^{*}}{Y}\left(1-e^{\frac{\mu_{\max } c_{t o l}}{c_{t o l}^{*}+K_{t o l}} t}\right)$

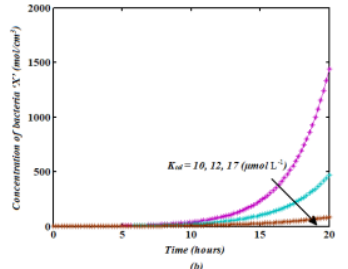

Fig. 2. Comparison of analytical expression of the concentration with simulation results and initial condition with various values of parameters $c_{t o l}^{*}=1, X^{*}=1, \mu_{\max }=4$, and $K_{t o l}=3$ when _ is analytical and, *** is numerical
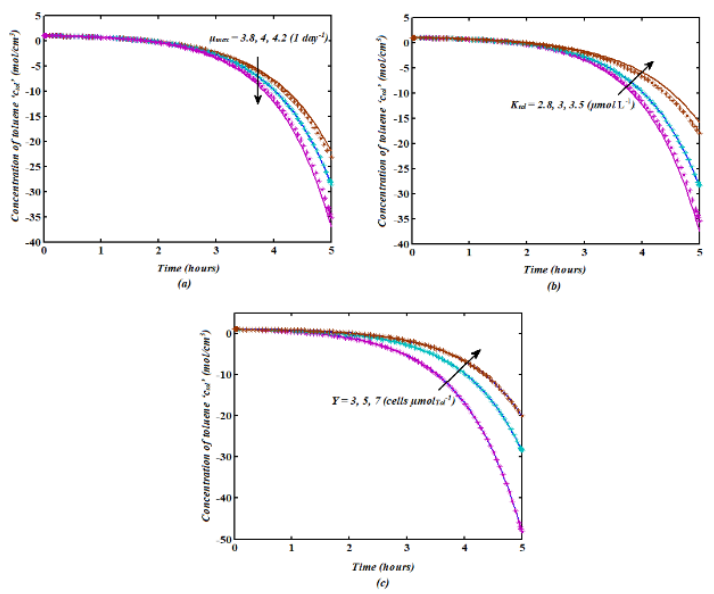

Fig. 3. Comparison of analytical expression of the concentration with simulation results and initial condition with various values of parameters $c_{t o l}^{*}=1, X^{*}=1, Y=5, \mu_{\max }=4$, and $K_{t o l}=3 \mathrm{when} \_$is analytical and, $* * *$ is numerical.

\section{Consideration of a metabolite}

In this model, we assume that the bacteria first transform toluene to a metabolite without growth, and then grow on the degradation of the metabolite. A suitable candidate metabolite is methyl-catechol. The revised equations read as follows [20]:

$$
\begin{aligned}
& r_{\text {tol }}=r_{\text {tol }}^{\max } \frac{c_{\text {tol }}}{c_{\text {tol }}+K_{\text {tol }}} \cdot X \\
& r_{\text {met }}=r_{\text {met }}^{\max } \frac{c_{m e t}}{c_{\text {met }}+K_{\text {tmet }}} \cdot X \\
& \frac{d c_{\text {tol }}}{d t}=-r_{\text {tol }} \\
& \frac{d c_{\text {met }}}{d t}=r_{\text {tol }}-r_{\text {met }}
\end{aligned}
$$




$$
\frac{d X}{d t}=Y \cdot r_{m e t}
$$

The initial conditions are $c_{\text {tol }}(t)=c_{\text {tol }}^{*}, c_{\text {met }}(t)=c_{\text {met }}^{*}, X(t)=X^{*}$ at $\quad t=0$

where $c_{t o l}[\mu M], c_{m e t}[\mu M]$, and $X\left[\right.$ cells $\left.L^{-1}\right]$ are concentration of toluene, metabolite and bacteria. Then $Y$ $[\mu M]$ and $K_{\text {tol }}[\mu M]$ are the half saturation concentration of yield coefficient and the toluene.

D. Analytical solutions of the consideration of a metabolite

In this work, the analytical expression of concentration of bacteria $X(t)$, toluene $c_{t o l}(t)$ and metabolite $c_{m e t}(t)$ are obtained as follows: $c_{t o l}(t)=c_{t o l}^{*} \cdot e^{-r_{t o l}^{\max }} \cdot \frac{c_{t o l} X^{*}}{c_{t o l}^{*}+K_{t o l}} \cdot t$

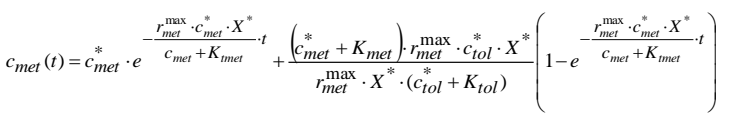

$$
X(t)=X^{*} \cdot e^{-\frac{Y \cdot r_{\text {met }}^{\max } \cdot c_{\text {met }}^{*} \cdot X^{*}}{c_{\text {met }}+K_{\text {tmet }}} \cdot t}
$$
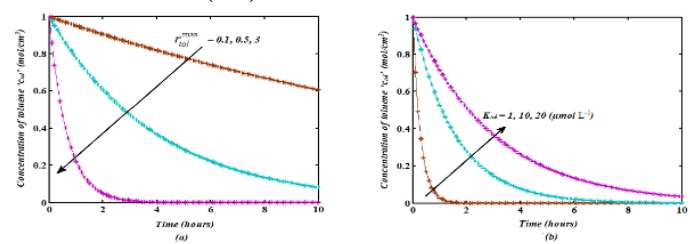

Fig. 4. Comparison of analytical expression of the concentration with simulation results and initial condition with various values of parameters $\left(c_{t o l}^{*}=1, X^{*}=1, r_{t o l}^{\max }=7\right.$, and $\left.K_{t o l}=1\right)$ when _ is analytical and, *** is numerical
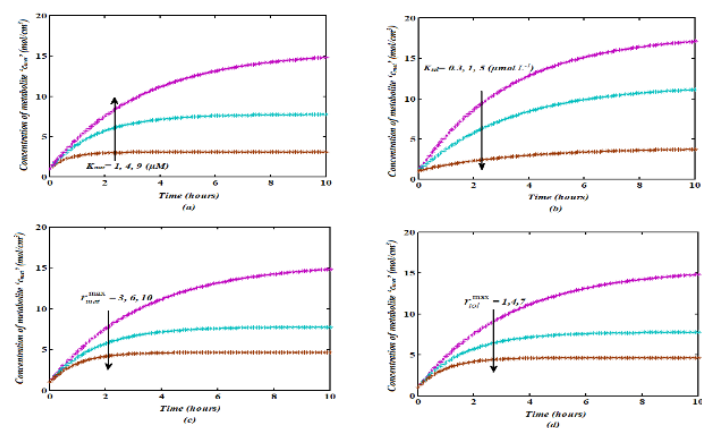

Fig. 5. Comparison of analytical expression of the concentration with simulation results and initial condition with various values of parameters $\left(c_{t o l}^{*}=1, X^{*}=1, c_{m e t}^{*}=1, r_{t o l}^{\max }=7, r_{m e t}^{\max }=3, K_{m e t}=9\right.$ and $\left.K_{t o l}=.5\right)$ when _ is analytical and, *** is numerical
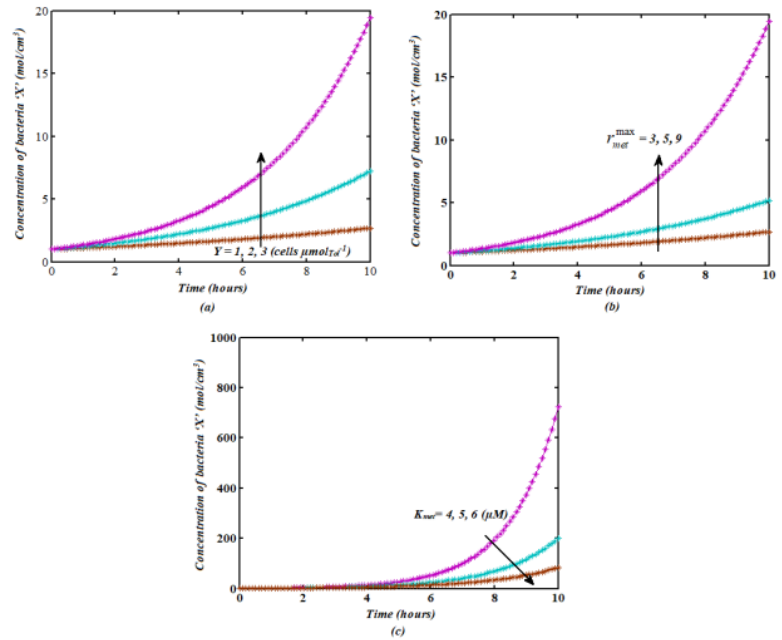

Fig. 6. Comparison of analytical expression of the concentration with simulation results and initial condition with various values of parameters $\left(c_{t o l}^{*}=1, X^{*}=1, c_{m e t}^{*}=0.1, r_{m e t}^{\max }=9, Y=3\right.$, and $\left.K_{m e t}=9\right)$ when _ is analytical and, *** is numerical. 


\section{MICROBIAL GROWTH}

Microbial growth is increased in cell size and frequent cell division. Many microbes have the enzymes and biochemical pathways required for all cellular synthesis Components are made from minerals and energy sources, biomass, nitrogen, phosphorus, and sulfur. Usually, the growth temperature ranges for a particular organism's spans from 30 to $40^{\circ} \mathrm{C}$. Some relations are delivered microbial growth in the groundwater system. The concentration of growth is below.

E. Reactive-transport modelling of Governing equations

We simulate microbial growth in the column systems coupled to one-dimensional reactive-transport with a numerical model that considers three mobile components, namely toluene oxygen, and suspended bacteria as well as the attached bacteria as immobile component. We model microbial growth of attached and suspended bacteria, depending on the simultaneous presence of toluene and oxygen, by dual Monod kinetics [20]:

$$
\begin{aligned}
& r_{\text {growth }}^{\text {att }}=\mu_{\text {max }} \cdot \frac{c_{t o l}}{c_{t o l}+K_{t o l}} \cdot \frac{c_{O x}}{c_{o x}+K_{O x}} \cdot X \\
& r_{\text {growth }}^{\text {mob }}=\mu_{\text {max }} \cdot \frac{c_{\text {tol }}}{c_{\text {tol }}+K_{\text {tol }}} \cdot \frac{c_{O x}}{c_{o x}+K_{o x}} \cdot X_{m o b} \\
& r_{\text {attach }}=K_{\text {att }} \cdot X_{\text {mob }} \cdot\left(1-\frac{X_{\text {att }}}{X_{\text {att }}^{\max }}\right) \\
& r_{\text {daughter }}=r_{\text {growth }}^{\text {att }} \cdot \frac{X_{\text {att }}}{X_{\text {att }}^{\max }}
\end{aligned}
$$

in which $\mu_{\max }\left[\mathrm{s}^{-1}\right]$ is the maximum specific growth rate constant, $c_{\text {tol }}$ and $c_{\text {ox }}[\mu M], X_{\text {att }}\left[L_{\text {sed }}^{-1}\right]$ and

$X_{m o b}\left[\right.$ cells $\left.L^{-1}\right]$ are the concentration of toluene, oxygen, attached, and mobile bacteria, respectively, whereas $K_{t o l}$ and $K_{o x}[\mu M]$ are the half-saturation concentrations of toluene and oxygen, respectively. In which $k_{\text {att }}\left[S^{-1}\right]$ is the first-order attachment rate coefficient and the term $\left(1-\frac{X_{\text {att }}}{X_{\text {att }}^{\text {max }}}\right)$ is introduced to account for the carrying capacity (Ding 2010). The rate of change of attached $X_{a t t}$ and mobile $X_{m o b}$ bacteria is described. It accounted for this process in the model by the dynamic detachment rate $r_{\text {daughter }}$ and attachment of suspended bacteria to the sediment surface is described by the modified first-order attachment rate $r_{\text {attach }}$.

One-dimensional transport of toluene and oxygen in the column system and their consumption due to growth of attached bacteria can be described by a system of coupled advection-dispersion-reaction equations [20]:

$$
\begin{aligned}
& \frac{\partial c_{\text {tol }}}{\partial t}=-\frac{1}{Y}\left(r_{\text {growth }}^{\text {att }}+r_{\text {growth }}^{\text {mob }}\right) \\
& \frac{\partial c_{o x}}{\partial t}=-\frac{f_{\text {ox }}}{Y}\left(r_{\text {growth }}^{\text {att }}+r_{\text {growth }}^{\text {mob }}\right) \\
& \frac{\partial X_{\text {att }}}{\partial t}=r_{\text {growth }}^{\text {att }}+n r_{\text {attach }}-r_{\text {daughter }} \\
& \frac{\partial X_{\text {mob }}}{\partial t}=-r_{\text {attach }}+\frac{1}{n} r_{\text {daughter }}
\end{aligned}
$$

where the microbial growth yield $Y$ and the ratio of stoichiometric coefficients of oxygen and toluene $f_{o x}$.

The initial condition becomes

$$
c_{\text {tol }}=c_{\text {tol }}^{*}, c_{o x}=c_{o x}^{*}, X_{\text {att }}=X_{\text {att }}^{*}, X_{\text {mob }}=X_{\text {mob }}^{*} \text { and } t=0
$$

$F$. Analytical solutions of the concentration toluene, oxygen, attached, and mobile bacteria

The analytical expression of concentration of toluene $\left(c_{t o l}\right)$, oxygen $\left(c_{o x}\right)$, attached $\left(X_{a t t}\right)$, and mobile bacteria $\left(X_{m o b}\right)$ are obtained as follows (Appendix. A):

$$
\begin{gathered}
c_{t o l}(t)=c_{t o l}^{*} \cdot e^{-\frac{\mu_{\max } \cdot c_{o x}^{*} \cdot\left(X_{a t t}^{*}+X_{\text {mob }}^{*}\right)}{Y \cdot\left(c_{t o l}^{*}+K_{t o l}\right)\left(c_{o x}^{*}+K_{o x}\right)} t} \\
c_{o x}(t)=c_{o x}^{*} \cdot e^{-\frac{\mu_{\max } \cdot c_{o x}^{*} \cdot f_{o x} \cdot\left(X_{a t t}^{*}+X_{m o b}^{*}\right)}{Y \cdot\left(c_{t o l}^{*}+K_{t o l}\right)\left(c_{o x}^{*}+K_{o x}\right)} t}
\end{gathered}
$$

$$
\begin{aligned}
& X_{a t t}(t)=X_{a t t}^{*} \cdot e^{\left(\frac{\mu_{\max } \cdot c_{o x}^{*} \cdot c_{t o l}^{*} \cdot}{Y \cdot\left(c_{t o l}^{*}+K_{t o l}\right)\left(c_{o x}^{*}+K_{o x}\right)}\right)\left(1-\frac{X_{a t t}^{*}}{X_{m o b}^{*}}\right) t}+ \\
& \frac{n \cdot k_{a t} \cdot X_{m o b}^{*}}{\mu_{\max }}\left(1+\frac{k_{o x}}{c_{o x}^{*}}\right)\left(1+\frac{k_{o x}}{c_{t o l}^{*}}\right) \cdot e^{\left(1-\left(\frac{\mu_{\max } \cdot c_{o x}^{*} \cdot c_{t o l}^{*}}{Y \cdot\left(c_{t o l}^{*}+K_{t o l}\right)\left(c_{o x}^{*}+K_{o x}\right)}\right)\left(1-\frac{X_{a t t}^{*}}{X_{m o b}^{*}}\right) t\right)}
\end{aligned}
$$




$$
\begin{aligned}
& X_{m o b}(t)=X_{m o b}^{*} \cdot e^{-\left(k_{a t t}\left(1-\frac{X_{a t t}^{*}}{X_{m o b}^{*}}\right)\right) t}+ \\
& \left(\frac{\mu_{\max } \cdot c_{o x}^{*} \cdot c_{t o l}^{*} \cdot\left(X_{a t t}^{*}\right)^{2}}{k_{\text {att }} \cdot\left(X_{\text {att }}^{\max }-X_{a t t}^{*}\right) n \cdot\left(c_{t o l}^{*}+K_{t o l}^{*}\right)\left(c_{o x}^{*}+K_{o x}\right)}\right)\left(1-e^{-\left(k_{a t t}\left(1-\frac{X_{a t t}^{*}}{X_{m o b}^{*}}\right)\right) t}\right)
\end{aligned}
$$
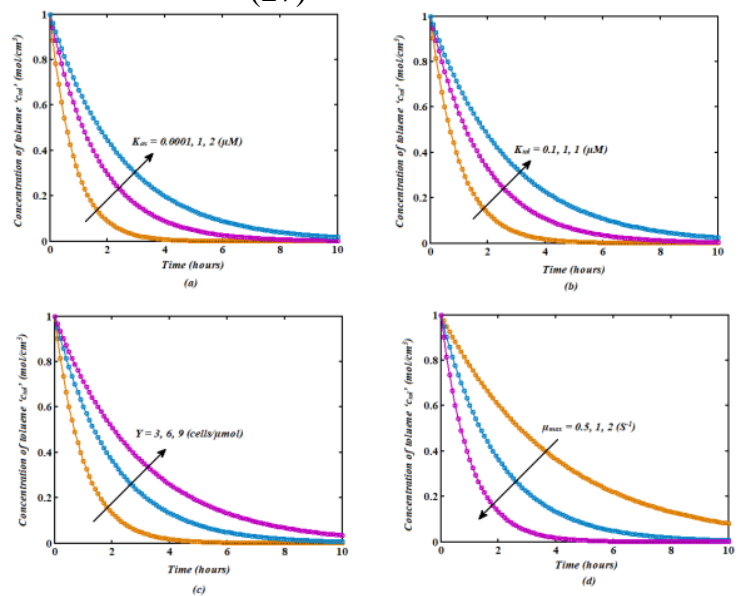

Fig. 7. Comparison of analytical expression of the concentration with simulation results and initial condition with various values of parameters

$\left(X_{\text {att }}^{*}=1, X_{\text {mob }}^{*}=1, c_{o x}^{*}=1, K_{t o l}=0.1, K_{o x}=0.2, \mu_{\max }=2\right.$ and $\left.Y=3\right)$ when __ is analytical and, ooo is numerical.
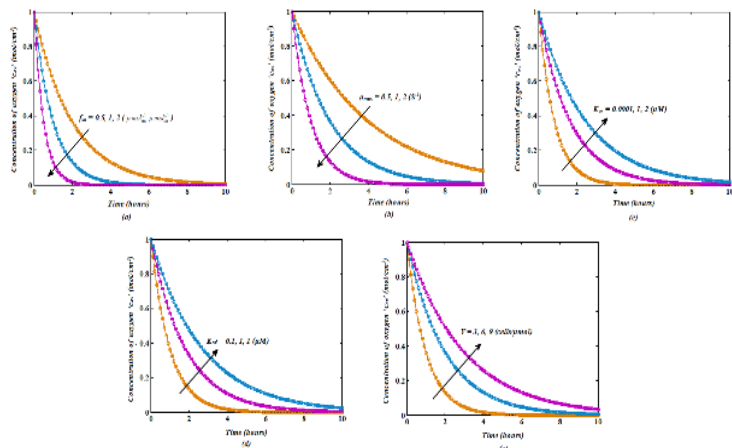

Fig. 8. Comparison of analytical expression of the concentration with simulation results and initial condition with various values of parameters $\left(X_{\text {att }}^{*}=1, X_{\text {mob }}^{*}=1, c_{O X}^{*}=1, K_{\text {tol }}=0.1, K_{O X}=0.2, \mu_{\max }=2, f_{\text {ox }}=1\right.$ and $\left.Y=3\right)$ when is analytical and, ${ }^{\text {ooo }}$ is numerical.
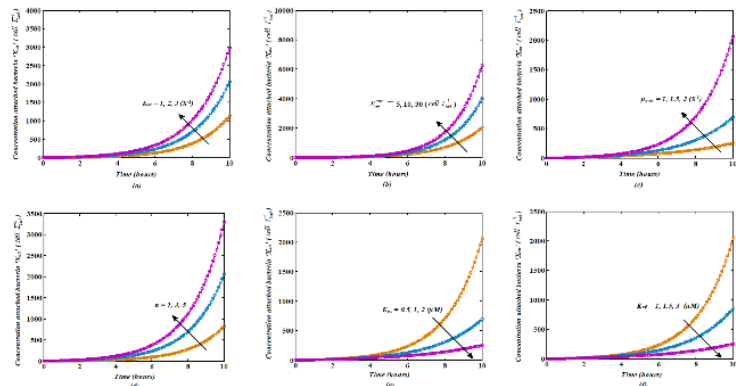

Fig. 9. Comparison of analytical expression of the concentration with simulation results and initial condition with various values of parameters $\left(X_{\text {att }}^{*}=1, X_{m o b}^{*}=1, c_{o x}^{*}=1, K_{t o l}=0.1, K_{o x}=0.2, \mu_{\max }=2, f_{o x}=1\right.$ and $\left.Y=3\right)$ when _ is analytical and, ${ }^{\circ o 0}$ is numerical. 

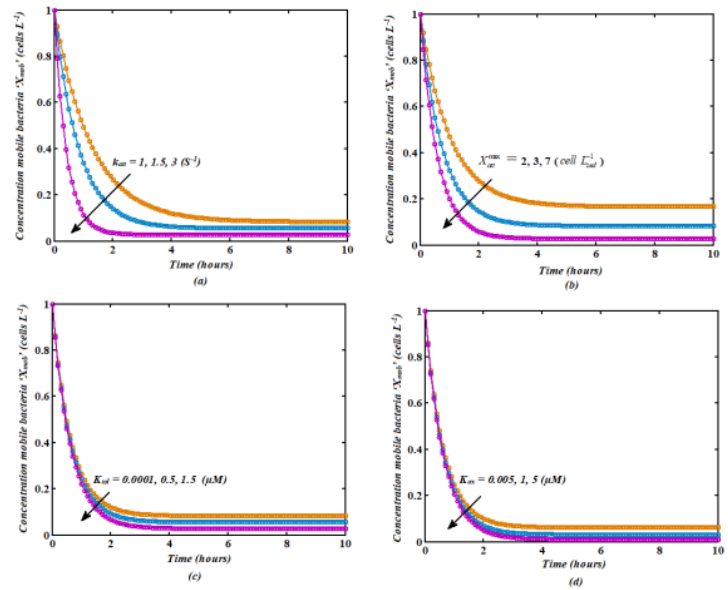

Fig. 10. Comparison of analytical expression of the concentration with simulation results and initial condition with various values of parameters

$\left(X_{\text {att }}^{*}=1, X_{m o b}^{*}=1, c_{o x}^{*}=1, K_{t o l}=0.1, K_{o x}=0.5, \mu_{\max }=2, X_{\text {att }}^{\max }=5, k_{a t t}=2\right.$ and $\left.n=2\right)$ when _ is analytical and, ooo is numerical.

\section{NUMERICAL SIMULATION}

A convenient way to introduce variable microbial kinetics in a numerical model is to describe growth dynamics with the help of Monod-type kinetics [21 - 23] Growth rates are then governed by the time-varying local concentrations of one or more reactive substances. The homotopy perturbation was first proposed by He et al. [24]. This method is used to find an approximate analytical solution of nonlinear problems. The non-linear differential Eqns. (1) - (3) have been solved numerically using MATLAB software. A respective script pdex4 is provided in Appendix-B. The analytical expressions of concentrations of $X(t), c_{t o l}(t), c_{m e t}(t), c_{o x}(t), X_{a t t}(t)$ and $X_{m o b}(t)$ are obtained from new homotopy perturbation method is compared with simulation results in graphs $(2-10)$. Satisfactory agreement is noted.

\section{RESULTS AND DISCUSSION}

The above solutions represent the new approximate analytical solutions for the concentration of bacteria and toluene, and metabolite for all values of parameters and Reactive-transport modelling is discussed. As time increases the parameter values coincide with the $\mathrm{x}$-axis. So the value of ' $\mathrm{t}$ ' is stopped after a particular period. Figure 2(a) shows the maximum specific growth rate constant on the concentration of the bacteria. From this figure, we observed that the concentration increases as the increasing value of a particular growth rate. Figure 2(b) illustrates different values of the parameter $K_{t o l}$ observed that the concentration increases with the increasing of the half-saturation concentration. Figure 3, represents the value of the ' $t$ ' values is five since the limit increases the error is also increased, so take lower values and higher values to apply the parameters and found the graph. Figure 3(a) illustrates the effect of maximum specific growth rate constant $\mu_{\max }$ on concentration profile. It represents the concentration profile is decreasing with increasing values of $\mu_{\max }$. As a result, its toluene coefficient decreases, and boundary decreases. Figures. 3(b) and 3(c), represents the concentration of toluene for different values of half-saturation concentration of the toluene and yield coefficient. It is observed that an increase in the parameters leads to an increase in concentration. This is the direct utilization of toluene for growth concentration. The gap between toluene inlet and outlet concentrations is initially increased, and then a steady value was reached, which we denote as the maximum efficiency of degradation.

In figures 4 to 6 , it is observed that there will not be any changes in the graph as t increases; hence the value $t$ is restricted. In these figures represented the consideration of metabolite concentrations. Figures 4(b), 5(a), 6(a), and 6(b) shows the effect of $K_{t o l}, K_{m e t}, Y$ and $r_{m e t}^{\max }$ on concentration profile. A high stoichiometric ratio fox translates into low carbon biomass yield. Hence, it was the highest yield with the lowest toluene mass flux under quasi-state conditions. It is noticed that while the values of the parameters are increasing the values of the concentration is decreasing.

This induces an increase in concentration. The effects of $r_{t o l}^{\max }, K_{t o l}, r_{m e t}^{\max }$ and $K_{m e t}$ on the concentration profile shown in Figs. 4(a), 5(b) to 5(d), and 6(c), where it is noticed that a decrease in the parameters leads to an increase in the metabolite concentration. Figures 7(a), 7(b) and 7(c) shows that the increase in the concentration of toluene ' $c_{t o l}$ ' that resulted from increasing parameters $K_{t o l}, K_{o x}$ and $Y$ is insignificant. From Figure $7(\mathrm{~d})$, it is observed that the concentration of toluene decreases when the Maximuxm specific growth rate constant $\mu_{\max }$ decreases. Figure 8(a) and 8(b), illustrates different values of Maximum specific growth rate constant $\mu_{\max }$ and 
stoichiometric coefficients $f_{o x}$ observed that the concentration increases with the increasing of the parameters. Figures 8(c), 8(d) and 8(e) is inferred that a parameters $K_{t o l}, K_{o x}$ and $Y$ increases the concentrations of oxygen increases.

The concentration profiles of attached bacteria versus time are expressed in Figures 9(a)-9(f). From these Figures, it is inferred that the value of the concentration of attached bacteria $X_{\text {att }}$ decreases when the $K_{\text {tol }}$ and $K_{o x}$ increases. But the concentration of attached bacteria increases when the first-order attachment rate coefficient $k_{\text {att }}$, maximum carrying capacity of attached bacteria ' $X_{\text {att }}^{\max }$, , maximum specific growth rate constant ' $\mu_{\max }$ ' and ' $n$ ' is increases. Figures 10(a) - 10(d), illustrates the effect of parameters $k_{a t t}, X_{a t t}^{\max }, K_{t o l}$ and $K_{o x}$ on concentration profile. It represents the concentration profile is decreasing with increasing values of the parameters.

\section{CONCLUSION}

The system of differential equations has been formulated and solved analytically using the new Homotopy perturbation method for various values. This work is mainly derived from metabolite concentration, the microbial growth of attached and suspended bacteria, depending on the simultaneous presence of toluene and oxygen, and dual Monod kinetics system. The attached bacteria are responsible for the majority of the observed biodegradation. While attached cells were mainly responsible for toluene degradation, the release of cells into the pure water causes permanent inoculation of the aquifer downstream. The effects of various parameters on concentration profiles are discussed. The obtained results have a satisfactory agreement.

\section{ACKNOWLEDGMENTS}

The authors are also thankful to Shri J. Ramachandran, Chancellor, Col. and Dr.G.Thiruvasagam, ViceChancellor, Academy of Maritime Education and Training (AMET), Chennai, Tamil Nadu.

\section{REFERENCES}

1. Meckenstock RU, Elsner M, Griebler C, Lueders T, Stumpp C, Dejonghe W, Bastiaens L, Sprigael D, Smolders E, Boon N, Agathos S, Sorensen SR, Aamand J, Albrechtsen H-J, Bjerg P, Schmidt SI, Huang W, van Breukelen B (2015) Biodegradation: updating the concepts of control for microbial clean-up in contaminated aquifers. Environ Sci Technol 49:7073-7081.

2. Meckenstock RU, Lueders T, Griebler C, Selesi D (2010) Microbial hydrocarbon degradation at coal gasification plants. In: Timmis KN (ed) Handbook of hydrocarbon and lipid microbiology. Springer, Berlin. https://doi.org/10. 1007/978-3-540-77587-4_167.

3. Meckenstock RU, Mouttaki H (2011) Anaerobic degradation of non-substituted aromatic hydrocarbons. Curr Opin Biotechnol 22:406-414.

4. Eckert D, Ku "rzinger P, Bauer R, Griebler C, Cirpka OA (2015) Fringe-controlled biodegradation under dynamic conditions: quasi 2-D flow-through experiments and reactive transport modeling. J Contam Hydrol1 72: 100-111. https:// doi.org/10.1016/j.jconhyd.2014.11.003.

5. del Giorgio PA, Cole JJ (1998) Bacterial growth efficiency in natural aquatic systems. Ann Rev Ecol Syst 29:503-541.

6. Hofmann R, Griebler C (2018) DOM and bacterial growth efficiency in oligotrophic groundwater absence of priming and co-limitation by organic carbon and phosphorus. Aquat Microb Ecol 81:55-71.

7. Hofmann R, Gro "sbacher M, Griebler C (2016) Mini sediment columns and two-dimensional sediment flow-through microcosms: versatile experimental systems for studying biodegradation of organic contaminants in groundwater ecosystems. In: McGenity TJ et al (eds) Hydrocarbon and lipid microbiology protocols. Springer, Berlin. https://doi. org/10.1007/8623_2016_210.

8. Jordan FL, Sandrin SK, Frye RJ, Brusseau ML, Maier RM (2004) The influence of system complexity on bacterial transport in saturated porous media. J Contam Hydrol 74:19-38.

9. Mellage A, Eckert D, Gro "sbacher M, Cirpka OA, Griebler C (2015) Dynamics of aerobic toluene degraders in flowthrough systems under growth and starvation conditions. Evaluating the performance of water purification in a vegetated groundwater recharge basin maintained byshortterm pulsed infiltration events. Water Sci Technol 72 (11): 1912-1922. https://doi.org/10.2166/wst.2015.400.

10. D. Britz, R. Baronas, E. Gaidamauskait, F. Ivanauskas, Further Comparisons of Finite Difference Schemes for Computational Modelling of Biosensors, Nonlinear Analysis: Modelling and Control 14 (2009) 419-433.

11. Li, J., He, Z., 2015. Optimizing the performance of a membrane bio-electrochemical reactor using an anion exchange membrane for wastewater treatment. Environ. Sci. Water Res. Technol. 1, 355-362.

12. Ahmed, M., Hasan, C., Rahman, H., Hossain, M., Uddin, S., 2015. Prospects of using wastewater as a resource-nutrient recovery and energy generation. Am. J. Environ. Sci. 11, 99-114. 
13. Harvey RW, Smith RL, George L (1984) Effect of organic contamination upon microbial distribition and heterotrophic uptake in a Cape Cod, Mass., aquifer. Appl Environ Microbiol 48:1197-1202.

14. Bengtsson G (1989) Growth and metabolic flexibility in groundwater bacteria. Microb Ecol 18:235248.

15. Griebler C, Mindl B, Slezak D (2001) Combining DAPI and SYBR Green II for the enumeration of total bacterial numbers in aquatic sediments. Int Rev Hydrobiol 86:453-465.

16. Griebler C, Mindl B, Slezak D, Geiger-Kaiser M (2002) Distribution patterns of attached and suspended bacteria in pristine and contaminated shallow aquifers studied with an in situ sediment exposure microcosm. Aquat Microb Ecol 28:117-129.

17. Griebler C, Malard F, Lefe 'bure T (2014) Current developments in groundwater ecology-from biodiversity to ecosystem function and services. Curr Opin Biotechnol 27:159-167.

18. O.M. Kirthiga, L.Rajendran, Analytical expressions of the concentrations of Substrate, biomass, and ethanol for solid-state fermentation in biofuel production, Energy Technology, 2, 2014, pp.574-578.

19. Thamizh Suganya S, Balaganesan P, Rajendran L (2020) Mathematical Modeling of Bio electrochemical Wastewater Treatment Using Microbial Fuel Cells. International Journal of Scientific \& Technology 9: 376-380.

20. Michael Gro "sbacher. Dominik Eckert. Olaf A. Cirpka. Christian Griebler (2018) Contaminant concentration versus flow velocity: drivers of biodegradation and microbial growth in groundwater model systems. https://doi.org/10.1007/s10532-018-9824-2.

21. Brun, A., Engesgaard, P., Frind, E.O., 1994. A coupled microbiology-geochemistry transport model for saturated groundwater flow. In: Dracos, T., Stauffer, F. (Eds.), IAHR/AIRH Symposium on Transport and Reactive Processes in Aquifers, Zurich, Switzerland. A.A. Balkema, Rotterdam, pp. 457-462.

22. Chiang, C.Y., Dawson, C.N., Wheeler, M.F., 1991. Modeling of in situ biorestoration of organic compounds in groundwater. Transp. Porous Media 6, 667-702.

23. Kindred, J.S., Celia, M.A., 1989. Contaminant transport and biodegradation: 2. Conceptual model and test simulation. Water Resour. Res. 25, 1149-1160.

24. He J.H, (1999) Homotopy perturbation technique. Compt. Method. Appl. Mech. Engg, 178:257-262. 